\title{
An Investigation on Chinese Primary Teachers' Knowledge of Physical Occupational Health Problems
}

\author{
Ruiyi Jiang ${ }^{1, a}$ \\ ${ }^{1}$ Institute of Education, University of Reading, London Road, Reading, Britain \\ a1583765379@qq.com
}

\begin{abstract}
Occupational health problems are very common among teachers and can have serious consequences for a teacher's life. Much research has been done on the occupational health of teachers, and has analysed its types, causes, prevention and effects. The purpose of this study is to investigate the knowledge of Chinese primary teachers in dealing with occupational health problems. This study adopted a mixed methodology and conducts quantitative and qualitative analysis in the form of a questionnaire. Teachers from a public primary school in Ningxia Province, China, participated in this study, and a total of 73 questionnaires were used for analysis.The results show that Chinese primary school teachers as a whole have a relatively good knowledge of dealing with occupational health problems, regardless of age and years of work, and there is no significant difference between males and females. However, some information about occupational health is poorly understood by teachers. Many teachers suffer from two or more occupational health problems at the same time, and they expressed a desire to participate in training on occupational health care.
\end{abstract}

Keywords: Teachers' health, Teachers' occupational health problems

\section{INTRODUCTION}

\subsection{Background}

The purpose of this topic is to investigate the current extent of teachers' awareness when dealing with occupational health problems, which are widespread and have a negative impact on teachers. As Bicout et al. [1] claimed, work is an important factor affecting people's health. As a large part of people's lives are spent working, different occupational health problems may arise. Although many people will experience health problems in their lifetime anyway, the health problems of some are more serious due to the characteristics of their occupations. Teaching is a profession involving many physical and psychological challenges [2]. There is a heavy workload, involving such diverse tasks as dealing with students' behaviour, interacting with colleagues and communicating with parents to determine their levels of satisfaction [3]. Theses tasks put teachers under a great amount of psychological pressure, which may lead to physical health problems, such as insomnia. And holding one position or talking loudly for a long time may also have a negative impact on their musculoskeletal and vocal health [4].
According to Scheuch [5], there are many kinds of occupational health problems for teachers, including musculoskeletal disorders, exhaustion, lack of concentration, sleep disorders, irritability, headaches and voice disorders. The impact of these difficulties can directly affect the quality of teaching, and in turn, the performance of students [6]. It may also explain why the percentage of teachers taking early retirement is much higher than those in the general population [7]. Therefore, this study will mainly investigate whether teachers have knowledge of how to deal with physical occupational health problems. Due to the wide variety of work-related illness among teachers, this study will only assess teachers' knowledge of three of the most common occupational health problems which some literature suggests can be alleviated and prevented by the teachers themselves working on a daily basis. The three are musculoskeletal disorders, sleep disorders and voice disorders. 


\subsection{Teachers' Common Occupational Health Problems}

\subsubsection{Musculoskeletal Disorders}

Musculoskeletal disorder (MSD) is one of the most common complaints [5]. It is generally a series of inflammatory and pathological changes that occur muscles, ligaments, and bones [8]. MSD can affect people's quality of life and reduce their work efficiency [9], and even lead to sick leave and early retirement in severe cases [10]. Furthermore, it also increases the financial burden of workers, as not only is the treatment painful, but also it is not cheap [11]. Therefore, it is necessary to prevent MSD wherever possible because it could cause chronic pain and hardship.

Many studies have investigated the causes of MSD. Erick and Smith [2] divided the factors into three categories, the individual factors, the physical activity factors and the psychological anxiety factors. They demonstrated that incorrect body posture, age and the length of working hours are factors relevant to MSD, which will aggravate the condition of workers. And the number and severity of these problems were higher in females. Other studies also suggested that, in addition to these factors, MSDs are also associated with smoking and drinking habits, the act of lowering the head for a long time to read and high frequency repetitive activity [12]. It should be noted that massage sometimes does not relieve MSDs but may aggravate the patient's pain [13]. All of the above factors may lead to and exacerbate musculoskeletal health problems in workers.

Teachers have been identified as a profession with a high prevalence of MSD. Erik and Smith [2] revealed that the proportion of teachers with MSDs ranged from $39 \%$ to $95 \%$. Yue et al. [14] found that the prevalence of neck and shoulder pain among Chinese teachers is $66.7 \%$, and the prevalence of teachers' neck, shoulder and back pain was higher, at $68.9 \%, 73.4 \%$ and $59.2 \%$, respectively. The reason for teachers suffering from MSD is that teachers tend to maintain a position for a long time and keep repeating those movements, resulting in repetitive strain injury, which affects their musculoskeletal health [15]. For instance, teachers generally stand for a long time in class, sometimes they have to raise their hands to write on the board for a long time, and these kinds of actions are repeated on a daily basis. At the same time, a teachers' work is not only to attend classes, but also to do a lot of work after classes. Tasks such as preparing lessons, correcting students' homework and reading frequently involve a lot of headbending that is not healthy for the shoulder, neck, and back. In this way, teachers accumulate long hours and a heavy workload, so making them more likely to be susceptible to MSDs which can then affect their health [2]. These are the reasons why teachers are vulnerable to MSDs and why some of them retire early.
Prevention of musculoskeletal problems is necessary in early adulthood and throughout the working life. Young workers particularly should be protected against MSDs caused by heavy work, and there are some strategies could prevent and mitigate them. Yue et al. [14] stated that preventing MSDs requires effective prevention strategies, which can be addressed in terms of individual, ergonomic and occupational factors. For instance, it is important to coach workers on how to recover from heavy work tasks using some recovery exercises [16]. Regular physical activities, such as yoga and cycling, can ease the pain and have a positive impact on musculoskeletal health [17]. It's also helpful to avoid standing and sitting for long periods of time and to take regular breaks [18]. Due to the occupational characteristics of teachers, this one is not always easy to fit within the teachers' timetable, but the school could arrange for teachers' class times to be more evenly distributed, so as to avoid teachers having many classes continuously and to ensure that teachers have time to rest. These methods can be applied throughout their working lives. While not a complete cure for severe MSDs, these strategies are useful for relieving pain and thus improving teacher effectiveness.

\subsubsection{Sleep Disorders}

Sleep disorders are defined as people having difficulty falling asleep, difficulty maintaining sleep, and lethargy. Different people have different symptoms, for some maybe the sleeping time follows an abnormal pattern, for others it may be that the quality of sleep is not good. It can be characterized by trouble sleeping, frequent awakenings, waking up too early to fall asleep again or feeling tired after waking up [19]. Sleep disorder could account for a high proportion in occupational health problems. According to Ohayon [20], 10 to 15 percent of people suffer from sleep disorders. Some people can suffer from sleep disorders for more than a decade [21]. Sleep disorders can not only affect rest at night, but also have a significant impact on daily functioning during the day, such as decreased quality of life, performance and physical function, and can even lead to mental illness. There are also significant economic costs associated with sleep disorders, such as reduced productivity, poor mental ability to concentrate and even work-related injuries, as well as medical costs [21].

The causes of sleep disorders have been explored by many researchers. Firstly, gender, age, marital and socioeconomic status were the most important factors in sleep disorders [22]. Lifestyle factors such as smoking, drinking, fatigue and depression are also important, and it is found that insomnia is one of the main symptoms of depression [20]. Secondly, some studies have found that people with sleep disorders tend to fall into a light sleep, meaning that they are more sensitive to stimuli, wake up 
more easily and take longer to fall back into sleep. This is due to tension before bedtime and the high level of brain activity during sleeping, so that such patients maintain a more awake state than those who do not suffer from sleep disorders. Therefore, people should stay in quiet places before bed and avoid stimulating behaviours such as reading, watching TV and drinking alcohol [23]. Finally, plenty of evidence points to stress as an important factor in sleep disorders [24]. Interestingly, the specific pathological causes of sleep disorders have not been identified and further research is needed. Despite the massive increase in interventions to promote sleep quality, sleep disorders still plague many sufferers. The most important thing to help prevent sleep disorders is having a regular sleep schedule [21].

Sleep disorders are common among teachers. Cheng et al. [25] found that teachers with sleep disorders accounted for about $40 \%$ of teachers in China, especially those who have worked for less than 10 years and those facing retirement. This is mainly because teachers who have not been working for a long time are under great psychological pressure when facing challenges in the workplace, and the teachers who are going to retire are often worried about their future. In addition, teachers are under considerable pressure from their heavy workload. Some teachers find they have to take their work home, bringing negative emotions into their household, thus affecting their sleep quality [26]. It can be seen that many teachers are under intolerable pressure in both physical and psychological aspects. A relentless workload and dealing with the relationships with parents and colleagues, while at the same time taking care of their own families, all of these could make restful sleep difficult for some teachers leading to a deterioration in their mental state.

There are two main treatments for sleep disorders, pharmacotherapy and behavioural therapy [21]. Behavioural therapy differs from pharmacological therapy in that it does not use drugs but is a treatment that requires an alteration in the patient's behaviour. Smith et al. [27] found that the outcomes of behavioural therapy were better than those of pharmacological therapy, and the effects lasted longer. There are two behavioural therapies that are very popular. One is progressive muscle relaxation, which involves relaxing a part of the muscle, then gradually spreading to the rest of the body, and finally relaxing the whole body. This is a treatment that patients could use at home [28]. The other one is a paradoxical intention to divert the patient's attention from sleep to other things. In this method, patients will not force themselves to fall asleep, and as they are then not thinking about the consequences of insomnia, so the stress of not being able to sleep will be reduced[27]. All of the above methods can effectively relieve sleep disorders.

\subsubsection{Voice Disorders}

The definition of voice disorder includes difficulty in voice use, loss of voice, and pathological voice health problems [29]. According to Angelillo et al. [30], the frequency of voice disorders is about $8.7 \%$. They are not easy to cure and may evolve into a chronic health problem lasting a lifetime. Teachers are more likely to suffer from voice disorders than other professions and the ailment is directly related to their work because they are voice users. As a result of this complaint, some teachers are not able to continue to work, and in some serious cases, even consider changing career [31]. Vocal disorders can develop into pathological changes, such as upper respiratory tract infections and vocal nodules, which sometimes need surgical treatment [32].

There are many factors could cause voice disorders. Kovacic [32] divided the causes into four types. The first is the organ factor, due to respiratory tract infection and other pathological health problems of the organs causing dysphonia. Then there are some environmental factors, such as harsh dry weather conditions and noisy environments that require talking loudly, which can make the voice user's throat uncomfortable. Next, voice disorders can result from improper vocalizations, such as voice abuse and voice overuse (e.g. singing loudly, screaming, talking loudly, etc.) that take the vocal cords beyond their comfort range. The last one is that anxiety for psychological reasons can also cause disorders in the voice because anxiety can cause illness such as inflammation of the throat. Kovacic [32] also found that smoking, coughing and spicy food were also important factors which could result in voice disorders.

Teachers use their voices extensively, and teachers also have a large proportion of voice disorders [31]. Among teachers, only $20 \%$ do not have voice problems, which is possibly one of the reasons why they have high rates of sickness and early retirement [4]. The profession requires them to speak frequently and at high volume for lengthy periods in order to allow every student in the class to hear clearly. Sometimes it is necessary to raise the volume to maintain discipline, so the damage to the vocal cords can be serious [32]. At the same time, noise in the classroom is also a significant factor, as some classroom environments may not be suitable for teaching, if the echo is not strong. In this situation, teachers need to speak louder, and this is more damaging to the voice. Furthermore, according to Kovacic [32], teachers are prone to voice fatigue, because they speak approximately three times more than other professions, mostly at high volume, over a long period of time making voice disorders more likely to occur.

Voice disorders can be pathologically treated, but prevention strategies can also alleviate or even cure them. Duffy and Hazlett [33] found that it is beneficial 
for teachers to receive training related to voice disorders. If teachers identify their symptoms early on and use correct methods to intervene, damage can be prevented [4]. For instance, frequent sore throats and long-lasting hoarseness are obvious symptoms, and when these symptoms occur, teachers should see a doctor as soon as possible [4], otherwise more serious conditions such as lesions can develop, which need to be treated with surgery. Ice and spicy food are not conducive to the recovery of voice complaints because they can cause irritation to the throat and vocal cords. It is worth mentioning that water, which is a common thing, and the humidity of the surrounding environment can have a great effect on voice care. Lack of moisture in the vocal cords will reduce mucus secretion, and a lack of mucus will increase friction between the vocal cords resulting in redness [34]. In addition, the use of loudspeakers is also a good way to ease the voice health problems. Teachers should recognise that it is necessary to take some preventive measures to reduce the risk of voice problems.

\subsection{Implication of the Study}

Although the consequence of occupational health problems can be serious, the worst cases are the result of long-term practice and early intervention can alleviate symptoms. Scheuch et al. [35] claimed that prevention could contribute to early detection and have a positive impact on health, to the benefit of both teachers and schools. Kovacic [32] also claimed that most voice problems can be prevented and avoided with voice care. Duffy and Hazlett [33] found that voice care was extremely beneficial to recovery. Other research found that many teachers are interested in voice training and satisfied with the results of it. It means that teachers want to take part in this kind of training discussed by Kovacic [36]. Musculoskeletal disorders and sleep disorders could also be mitigated by raising teachers' awareness of care. Yet, it is worth noting that there is little training on occupational health problems for teachers, something which should be paid attention to and promoted. By understanding the current situation of Chinese primary school teachers' knowledge with regard to occupational health problems and combining this with the conclusions of other studies, this study can help teachers to alleviate occupational health problems more effectively.

However, all the above studies analysed the current situation, causes and treatment of occupational health problems of teachers. But there is a gap in that there has been little or no research to investigate teachers' knowledge of occupational health problems. Kovacic
[32] analysed the voice care knowledge among teachertraining students and found that these students still needed to supplement their understanding of voice care. Other aspects of occupational health awareness also need to be supplemented. It is also helpful to investigate the teachers' knowledge for their further training.

This research investigates the following 3 questions:

1. Do Chinese teachers have knowledge of dealing with occupational health problems and what factors could contribute to them?

2. What kind of misjudgements are Chinese teachers more prone to making, leading to occupational health problems?

3. What are Chinese primary teachers' health status and what is their attitude toward it?

\section{METHODOLOGY}

\subsection{Research Approach}

In this study, a mixed method was adopted, including qualitative and quantitative methods. A questionnaire was used as the research instrument because this study requires a large number of samples in order to reflect the current status of Chinese primary school teachers' knowledge on occupational health issues. Meanwhile, 30 related items are included in the questionnaire to investigate their knowledge in order to achieve the aim of this study. The questionnaire can be used to quickly and conveniently to obtain the data the researcher wants. At the end of the questionnaire in this research, two open questions were designed to investigate Chinese primary teachers' health status and attitude towards it, so as to further understand their feelings and needs. Therefore, although the questionnaire was the only instrument, in essence, this research adopted the mixed method.

\subsection{Research Design and Data Collection}

Kovacic [32] investigated the knowledge of teachertraining students about voice care by means of questionnaire, so as to judge whether teacher-training students have sufficient knowledge to conduct voice care strategies and compared them with people engaged in other professions. This study drew on that questionnaire, including 5 parts and took each participant about 15 minutes to complete. The questionnaire has shown below. 
Table 1 The Questionnaire

\begin{tabular}{|c|c|c|c|c|}
\hline \multicolumn{5}{|c|}{ Part ONE: } \\
\hline \multicolumn{5}{|c|}{ Part TWO: } \\
\hline $\mathbf{N}$ & Items & Tru & Fals & DK \\
\hline 1 & Shouting could affect voice & & & \\
\hline 2 & Smoking will not affect voice & & & \\
\hline 3 & Drinking water has little effect on voice care & & & \\
\hline 4 & Often clearing throat with a small cough is good for voice & & & \\
\hline 5 & Speaking loudly is not good for voice & & & \\
\hline 6 & Only medications could cure voice disorders & & & \\
\hline 7 & Gene strictly determine the voice and it is not possible to develop it & & & \\
\hline 8 & Eating spicy food is not good for the voice & & & \\
\hline 9 & Frequent or long-lasting sore throats usually is not a kind of voice disorders & & & \\
\hline 10 & Coughing could affect the voice & & & \\
\hline \multicolumn{5}{|c|}{ Part THREE: } \\
\hline $\mathbf{N}$ & Items & Tru & Fals & DK \\
\hline 1 & Sleep disorders could increase the risk of other health problems & & & \\
\hline 2 & Exercise helps with better sleeping & & & \\
\hline 3 & If people have insomnia, they should wake up later the next day to get enough sleep & & & \\
\hline 4 & Sleep disorders can only be treated with medication & & & \\
\hline 5 & Reading and watching TV are good for getting into sleep & & & \\
\hline 6 & Insomnia can be a sign of depression & & & \\
\hline 7 & More stress leads to more fatigue therefore results in more sleep & & & \\
\hline 8 & Drinking could make me lose sleep & & & \\
\hline 9 & Noisy environments before bed could make me feel tired and sleep better & & & \\
\hline 10 & Frequent awakenings are one of sleep disorders & & & \\
\hline \multicolumn{5}{|c|}{ Part FOUR: } \\
\hline $\mathbf{N}$ & items & Tru & Fals & DK \\
\hline 1 & Shoulder and neck problems can cause headache or dizzy & & & \\
\hline 2 & $\begin{array}{l}\text { Patients with musculoskeletal disorders should not exercise as it will aggravate } \\
\text { health problems }\end{array}$ & & & \\
\hline 3 & Keeping a posture for a long time can lead to musculoskeletal disorders & & & \\
\hline 4 & Very soft mattresses and pillows are good for musculoskeletal relief & & & \\
\hline 5 & Cold will not cause musculoskeletal disorders & & & \\
\hline 6 & Musculoskeletal disorders are normal as you age, so you don't need to see a doctor & & & \\
\hline 7 & Diet and alcohol have no effect on musculoskeletal disorders & & & \\
\hline 8 & Proper rest can relieve musculoskeletal disorders & & & \\
\hline 9 & Massage is not necessarily good for musculoskeletal health & & & \\
\hline 10 & Different occupational health problems are not related & & & \\
\hline \multicolumn{5}{|c|}{ Part FIVE: } \\
\hline \multicolumn{5}{|c|}{$\begin{array}{l}\text { 1. What kind of physical discomfort do you feel at work due to your occupation? What kind of occupational } \\
\text { health problems do you have? }\end{array}$} \\
\hline & $\begin{array}{l}\text { you think it is useful and helpful for teachers to take part in a training on occupational } \\
\text { lth problems? }\end{array}$ & YES & $\mathrm{NO}$ & \\
\hline 2. & $\begin{array}{l}\text { If you select "yes", what training topics you are interested in? what is the best way to t } \\
\text { some ideas. }\end{array}$ & & & \\
\hline
\end{tabular}

\section{***The incorrect items are in italics for the reader's understanding}

When designing the questionnaire, in order to lessen the content and shorten the amount of time participants needed to spend on its completion, most of the items consist of short true or false statements, in the hope of improving the return and completion rate. The first part concerns descriptive statistics, including the age, gender and working years of participants. Parts 2-4 asks participants to choose the answer, which is more relevant to them, a total of 30 items in all. Items 1 to 10 are about voice disorders, 11 to 20 are about sleep disorders, and 21 to 30 are about musculoskeletal disorders. Each item related to three options, "True", 
"False" and "I don't know". The "I don't know" option could increase the validity of the study by avoiding random selection of participants due to uncertainty. As the content of this study also included voice care, some typical items about common voice care were selected from Kovacic's [32] questionnaire. Additional items on musculoskeletal disorders and sleep disorders were added, all of them from the literature review above or common knowledge. Since the purpose of this research was to investigate Chinese primary teachers' knowledge of physical occupational health problems, rather than selecting a high-level specialist in occupational health care, the items should not be too specialized or difficult. Therefore, all the items tended to be about common elements in daily life that can result in occupational health problems which can accumulate. In the fifth part, two open questions were added at the end of the questionnaire to investigate the participants' health status and their feelings about teachers' occupational health problems.

After designing the questionnaire, there was a pilot study. Since participants in this research are Chinese primary teachers, a Chinese teacher completed the Chinese version of the questionnaire and gave feedback to ensure that the questions were clear and could be understood. According to the teacher's feedback, all contents of the questionnaire were clear and not too difficult and were about everyday situations which people often encounter in life. The questionnaire was not too long to make participants want to give up completing it as well. Therefore, the questionnaire could be used for data collection.

The data was collected by posting the questionnaire on the "Wenjuanxing", a Chinese website dedicated to the questionnaire. The researcher copied the link of the questionnaire to the principal, who then shared the link with other teachers on WeChat Application.

\subsection{Sample}

The study was conducted in Yinchuan, Ningxia Province, in northwest China. All participants work at the large-scale public primary School. This school was chosen because it is a typical public Chinese primary school, which is similar to most public primary schools in China in terms of the source of teachers, the proportion of different genders and ages, and the working processes, so it is representative. And it is near the area where the researcher is located, so it is convenient to collect data. The teachers volunteered to take part in the anonymous study after the headmaster sent a link to their WeChat group. A total of 79 teachers from different grades, subjects, age groups, lengths of service and from both genders participated in this research. Most of the participants are females, which may be due to the male-female ratio of Chinese teachers. The participants in this research were all educated teachers, so it was anticipated that they could access the questions or use assistive technology to have the questions read out to them or access support in writing their responses.

Before analysing the data, the researcher had a quick look at the received responses. Six of the questionnaires were classified as invalid questionnaires due to the incompletion, so the data of six questionnaires was disregarded. Therefore, there were 73 completed questionnaires used for data analysis in the end.

\section{RESULTS}

\subsection{Introduction}

The first part of the questionnaire is devoted to descriptive statistics, investigating the gender, age and working years of the participants, and determining whether these factors had an impact on knowing how to cope with occupational health issues. The researcher calculated the number and proportion of participants by different gender, different age ranges and different numbers of years worked (see Table 2).

Table 2 Descriptive Statistics

\begin{tabular}{cccc}
\hline Participants & Types & Num & Percentage \\
\hline Gender & Male & 9 & $12.33 \%$ \\
& Female & 64 & $87.67 \%$ \\
Age & $21-30$ & 23 & $31.51 \%$ \\
& $31-39$ & 23 & $31.51 \%$ \\
Working Years & $40-49$ & 24 & $32.88 \%$ \\
& Above 50 & 3 & $4.11 \%$ \\
& $1-9$ & 32 & $43.84 \%$ \\
& $10-19$ & 19 & $26.03 \%$ \\
$\mathrm{~N}$ & $20-29$ & 19 & $26.03 \%$ \\
& $30-39$ & 3 & $4.11 \%$ \\
& & 73 & - \\
\hline
\end{tabular}

\subsection{Key Findings (related to the first research question)}

Thirty items were set up in the second to fourth parts of the questionnaire to determine whether the participants had the knowledge to handle health issues caused by teaching. In order to answer the first research question, the researcher respectively calculated the total accuracy rate of the questionnaire, the number of correct answers of each participant, and the proportion of each participant in different number categories. The researcher classified the number of correct answers, which were linked to their level of knowledge of occupational health issues. More than 25 correct answers were classified as "Very Good", "Good"(2125), "Relatively Good" (16-20), "Not Good" (10-15) and "Poor" (less than 10).

On average, the 73 participants answered 20 items correctly, the total average accuracy rate was $66.67 \%$. 
There was only one person who gave fewer than 10 correct answers (1.4\%). 7 people gave between 10 and 15 correct answers $(9.6 \%) ; 28$ people gave between 16 and 20 correct answers (38.4\%); the majority of people gave 21-25 correct answers (49.3\%). Only one participant correctly answered more than 25 items (1.4\%). Most of the participants had a good or relatively good accuracy rate, while a few had low accuracy rates.

In order to determine whether participants' ages and working years have an impact on their knowledge of occupational health problems, the researcher correlated each participant's age and working years with their total questionnaire scores. The correlation coefficient between age and total score is -0.017 , and the sig value is 0.889 . Since the sig value is greater than 0.005 , there is no significant relationship between ages and total scores. In addition, the results of the correlation analysis between their working years and total scores, with their correlation coefficient of 0.009 and sig value of 0.940 . As sig value is greater than 0.05 , there is no significant correlation between working years and total scores. Therefore, the questionnaire scores were not affected by the participants' ages and working years.

To investigate whether the gender factor has an impact on Chinese primary teachers' knowledge of occupational health issues, the researcher calculated the correct rates of males and females for each item (see Table 3). In order to facilitate the analysis, the researcher coded the complex item long sentences as the factors to be examined in each item. They are a word or a simple phrase for displaying the results of a data analysis. As show below, males' total average accuracy rate was $69.29 \%$, while that of the females was $73.17 \%$, slightly higher than males, but the difference was not significant. However, in some items, the accuracy of males and females varies greatly.

Table 3 Correct Rates of Different Items

\begin{tabular}{|c|c|c|c|c|c|}
\hline No & Label & Male & Female & Total & DK \\
\hline 1 & Shouting & $88.89 \%$ & $98.41 \%$ & $97.26 \%$ & $1.37 \%$ \\
\hline 2 & Smoking & $66.67 \%$ & $93.65 \%$ & $90.41 \%$ & $0 \%$ \\
\hline 3 & Water & $77.78 \%$ & $74.6 \%$ & $75.34 \%$ & $13.30 \%$ \\
\hline 4 & Clearing throat & $11.11 \%$ & $25.4 \%$ & $24.66 \%$ & $36.99 \%$ \\
\hline 5 & Speaking loudly & $88.89 \%$ & $90.48 \%$ & $90.41 \%$ & $5.48 \%$ \\
\hline 6 & Voice medications & $11.11 \%$ & $20.63 \%$ & $20.55 \%$ & $34.25 \%$ \\
\hline 7 & Gene & $77.78 \%$ & $80.95 \%$ & $80.82 \%$ & $16.44 \%$ \\
\hline 8 & Spicy food & $100 \%$ & $92.06 \%$ & $93.15 \%$ & $5.48 \%$ \\
\hline 9 & Sore throats & $55.56 \%$ & $69.84 \%$ & $68.49 \%$ & $19.18 \%$ \\
\hline 10 & Coughing & $77.78 \%$ & $88.89 \%$ & $87.67 \%$ & $5.48 \%$ \\
\hline 11 & Increase risk & $100 \%$ & $98.41 \%$ & $98.63 \%$ & $1.37 \%$ \\
\hline 12 & Exercise & $100 \%$ & $100 \%$ & $100 \%$ & $0 \%$ \\
\hline 13 & Wake up & $44.44 \%$ & $57.14 \%$ & $56.16 \%$ & $8.22 \%$ \\
\hline 14 & Sleep medication & $66.67 \%$ & $77.78 \%$ & $76.71 \%$ & $17.81 \%$ \\
\hline 15 & Reading \& watching TV & $44.44 \%$ & $36.51 \%$ & $36.99 \%$ & $24.66 \%$ \\
\hline 16 & Depression & $77.78 \%$ & $34.92 \%$ & $39.73 \%$ & $32.88 \%$ \\
\hline 17 & Stress & $55.56 \%$ & $49.21 \%$ & $49.32 \%$ & $17.81 \%$ \\
\hline 18 & Drinking & $55.56 \%$ & $20.63 \%$ & $24.66 \%$ & $45.21 \%$ \\
\hline 19 & Noisy environment & $77.78 \%$ & $92.06 \%$ & $89.04 \%$ & $8.22 \%$ \\
\hline 20 & Frequent awakenings & $66.67 \%$ & $92.06 \%$ & $89.04 \%$ & $8.22 \%$ \\
\hline 21 & Headache \& Dizzy & $88.89 \%$ & $95.24 \%$ & $94.52 \%$ & $5.48 \%$ \\
\hline 22 & Exercise & $33.33 \%$ & $44.44 \%$ & $42.47 \%$ & $36.99 \%$ \\
\hline 23 & Posture & $100 \%$ & $93.65 \%$ & $93.15 \%$ & $6.85 \%$ \\
\hline 24 & Soft pillows & $66.67 \%$ & $76.19 \%$ & $73.97 \%$ & $17.81 \%$ \\
\hline 25 & Cold & $66.67 \%$ & $80.95 \%$ & $78.08 \%$ & $15.07 \%$ \\
\hline 26 & Normal & $88.89 \%$ & $92.06 \%$ & $91.78 \%$ & $2.74 \%$ \\
\hline 27 & Diet \& Alcohol & $77.78 \%$ & $88.89 \%$ & $86.30 \%$ & $10.96 \%$ \\
\hline 28 & Rest & $88.89 \%$ & $95.24 \%$ & $94.52 \%$ & $2.74 \%$ \\
\hline 29 & Massage & $44.44 \%$ & $49.21 \%$ & $47.95 \%$ & $20.55 \%$ \\
\hline \multirow[t]{2}{*}{30} & Related & $77.78 \%$ & $85.71 \%$ & $84.93 \%$ & $9.59 \%$ \\
\hline & Average & $69.26 \%$ & $73.17 \%$ & $72.56 \%$ & $14.37 \%$ \\
\hline
\end{tabular}

\subsection{Key Findings (related to the second research question)}

The second research question of this study is to investigate which specific items Chinese teachers are more prone to misjudging, so as to illustrate the lack of certain knowledge of them. The researcher added a column to Table 3 above to calculate the total accuracy for each item.

The accuracy rates of each item listed in Table 3 divided into five ranges. The first range, where the accuracy rates are less than $40 \%$ (Poor), include 
"Clearing throat", "Voice medications", "Reading \& Watching TV", "Depression" and "Drinking". The second range, where the accuracy rates range between $40 \%$ to $59 \%$ (Not Good), includes items "Wake up", "Stress", "Exercise" and "Massage". The third range, $60 \%$ to $79 \%$ (Average), includes "Water", "Sore throats", "Sleep medication", "Soft pillows" and "cold". The fourth range is between $80 \%$ to $99 \%$ (Good), and includes "Shouting", "Smoking", "Speaking loudly", "Gene", "Spicy food", "Coughing", "Risk", "Frequent awakenings", "Headache \& Dizzy", "Posture", "Normal", "Diet \& Alcohol", "Rest" and "Related". And the final range, the accuracy rate of the item "Exercise" was 100\%, accounting for $3.33 \%$. Consequently, the accuracy rates of 15 items was between $80 \%$ and $99 \%$, accounting for $50 \%$; The accuracy rates of 5 further items ranged from $60 \%$ to $79 \%$, accounting for $16.67 \%$; The accuracy rates of 4 items ranged from $40 \%$ to $59 \%$, accounting for $13.33 \%$; The accuracy rates of 5 items was less than $40 \%$, accounting for $16.67 \%$. Most items are correct between $80 \%$ and $99 \%$ of the time. The proportions of accuracy rates were roughly the same for items that were less than $40 \%, 40 \%$ to $59 \%$ and $60 \%$ to $79 \%$. Accuracy of $100 \%$ is only $1.37 \%$.

The questionnaire for this study included knowledge of three occupational health issues: musculoskeletal disorders, voice disorders, and sleep disorders. Items 1 to 10 related to musculoskeletal disorders, 11 to 20 related to sleep disorders, and 21 to 30 related to musculoskeletal disorders. In order to measure which aspects of participants' knowledge were missing, the researcher calculated the accuracy rates for each of the three occupational health problems. The average correct rate was $78.77 \%$ for the musculoskeletal part, $72.88 \%$ for the voice disorders and $66.03 \%$ for the sleep disorders. According to the analysis results, the participants were most knowledgeable about musculoskeletal health, followed by voice health and least knowledgeable about sleep health.

In the 30 items in the second to fourth parts of this research questionnaire, in addition to the "True" and "False" options, the other option is "I don't know", which is used to investigate the real condition of Chinese primary teachers' occupational health problems. The percentage that each item is selected with the "I don't know" option is shown in Table 3 above. Although the overall average rate of the "I don't know" option is relatively low $(14.37 \%)$, the percentage of not knowing is still relatively high for some items, which means that participants are able to make a judgment on most items, while there is a significant lack of knowledge for a small number of items.

\subsection{Key Findings (related to the third research question)}

The last part of this study is qualitative investigation, which investigated the health status and attitudes of Chinese primary teachers. Fifty-seven participants answered the first question, and only two of them said they had no occupational health problems. According to the participants' responses, their existing occupational health problems are eye pain, listening difficulties, sore throat, loss of voice, anxiety, headache, depression, insomnia, lower back pain, varicose veins, knee pain, feet pain, neck and shoulder pain. This shows that the occupational health problems of teachers vary widely. The most frequent occupational health problem is neck and shoulder pain, which occurred in 47 people. The second largest number of participants reported sore throats, 22 of them. In addition, the occupational health problems with relatively high frequency are insomnia, lower back pain and anxiety, which occur with a frequency of 16, 15 and 10 respectively. Furthermore, twelve participants suffered from two occupational health problems at the same time, and 15 suffered from more than two occupational health problems. Nearly all of the participants reported feeling physically tired and suffering from some sort of work-related ailments.

The second question was to investigate whether participants thought it would be helpful and useful for them to take part in training on occupational health issues. A total of 58 participants, accounting for $79.45 \%$, believed that participating in some form of training will be helpful to them. Most of the participants are interested in training on neck, shoulder and throat health care along with mental health training. Quite a few participants were interested in training on how to relieve physical fatigue.

Some of the participants mentioned some specific needs. One participant stated,

"I hope the training content can be something we can do in our daily life, such as during the break between classes, so as to relieve our physical discomfort in a timely manner and will use our extra time..."

Another participant claimed "I hope that the content of the training can be some difficult and skilled exercises such as yoga. We usually do not have enough time, energy and money to attend such training...otherwise we may be injured and then exacerbate our health problems."

Two participants proposed that the training for occupational health issues not only requires theoretical knowledge, but also needs to combine some practical training programs. In this way, some bad habits can be corrected in time and implemented in detail. In particular, one participant expressed, 
"I hope that health care professionals could be invited to give us lectures. Because if it is an occupational health care training organized by our school, may send the wrong message to us..."

Another participant expressed a desire to be able to conduct face-to-face mental health counselling, "The psychological burden of stress and some symptoms such as insomnia did affect my performance at work. I hope that I can communicate with professionals face to face to relieve my psychological pressure, and they can teach me how to deal with these psychological problems."

It is worth mentioning that, one participant stated, "It will be better to be trained online or self-taught. Because the heavy workload makes us exhausted and such training could also consume our time and energy."

\section{DISCUSSION}

This study found that Chinese primary school teachers have relatively good knowledge when it comes to dealing with work-based health issues. The knowledge they demonstrated is unrelated to their age and working years, and there is no significant difference between different genders. Chinese primary school teachers appear to know less about sleep disorders, than about voice disorders and musculoskeletal disorders. Most of the teachers surveyed suffer from two or more occupational health problems and they want to participate in occupational health care training. These findings will be discussed in more detail below.

\subsection{Findings (related to the first research question)}

The first area of investigation was whether Chinese primary school teachers have the knowledge to deal with occupational health problems. According to the data collected from the questionnaire survey, Chinese primary school teachers as a whole have a relatively good knowledge of dealing with the occupational health problems that teachers may face. As mentioned above, this study follows from the research of Kovacic. Kovacic's [32] study only investigated voice disorders, whereas this study also included musculoskeletal disorders and sleep disorders common among teachers. However, the two studies reached different conclusions on this research question. Kovacic's [32] research believed that teacher training students do not have sufficient knowledge to deal with voice health problems of teachers, while the conclusion of this research is that teachers are relatively good at dealing with occupational health problems.

The factors influencing occupational health knowledge were also analysed in this study. Erick and Smith [2] studied the causes of the musculoskeletal disorder. Several factors which could influence complaints of this nature are gender, age and working years. Walsh [22] analysed the causes of the sleep disorder and found that gender and age were contributing factors here as well. On this basis, this study investigated whether gender, age and working years also have an impact on knowledge of dealing with these health problems. From the data, the researcher concluded that age and working years do not have effect on it. And on the whole, there is not much difference between different genders. Consequently, while these factors have an impact on occupational health status, they have no impact on teachers' knowledge of how to deal with these health issues. One possible reason is that these knowledge errors and blind spots might not be influenced by the aging process, but rather by training and education.

\subsection{Findings (related to the second research question)}

Regarding sleep disorders, Johnson et al. [23] found that excitement before bedtime could lead to a more awakened state. In this study, many teachers thought incorrectly that reading and watching TV or drinking alcohol before bed can help them fall asleep. Ohayon [20] found that insomnia is one of the main manifestations of depression, but many teachers in this study do not realise this. One of the most common misconceptions is believing that if people have insomnia, they should wake up later the next day to make up for it. However, in doing so they ignore the importance of a regular sleep pattern [21]. Some teachers believed that more stress leads to more fatigue therefore results in more sleep, while according to Bannai et al. [24], a lot of evidence points to stress as being one of the main causes of sleep disorders.

Regarding voice disorders, Kovacic [32] found that smoking and clearing the throat with a small cough could result in voice disorders. In this study, it is found that teachers mistakenly believed that frequent clearing throat with a small cough is beneficial for voice care. Many teachers thought voice disorders can only be treated with medication, while Roy and Bless [34] proved that such simple things as water, and the humidity of the surrounding environment can have a great effect on the voice care. Lack of moisture in the vocal cords will reduce mucus secretion, and in turn lack of mucus will increase friction between the vocal cords resulting in redness.

Regarding musculoskeletal disorders, some teachers believed that people with musculoskeletal disorders should not exercise because it could exacerbate their health problems. However, according to Halonen et al. [16] and Bogaert et al. [17], it is important to coach people on how to recover from heavy work tasks by way of recovery exercises. As regular physical activities, such as yoga and cycling, can ease the pain 
and have a positive impact on musculoskeletal health. Some teachers also overestimated the effects of massage on musculoskeletal health and were unaware that massage could sometimes have a negative impact on it [13].

In this study, Kovacic's [32] questionnaire was used for reference. Both sets of research set the option "I don't know" in the second to fourth parts of the questionnaire and come to the same conclusion that some knowledge is not misjudged by the teachers, but that the teachers did not have the knowledge of it.

\subsection{Findings (related to the third research question)}

According to the answers to the open questions in the questionnaire, most Chinese primary teachers are troubled by occupational health problems. There are various types and many teachers suffer from more than two difficulties at the same time. The most frequent are neck and shoulder pain, sore throat, back pain, insomnia and anxiety. According to previously published works, it is because teachers have a high workload and are consequently under a lot of pressure, which then leads to anxiety and insomnia. Additionally the job requires teachers to talk and maintain the same position for a long time, (i.e. standing, sitting and working with their heads bowed) [2][3][12][13][17].

Kovacic[36] found that most teachers want to have the opportunity to participate in the training on teacher occupational health care, which was consistent with the results of this study. This study further explores this and investigates the content and methods of training in which teachers are interested. Neck and shoulder pain relief, throat health care, mental health care and physical fatigue relief were all areas of concern. A few also mentioned daily care and yoga. Interestingly, besides the usual training medium of attending lectures, teachers also put forward other good suggestions. First of all, they think that a combination of theory and practical training will be more helpful than pure theory. Secondly, they believe that inviting professionals to give them training can give them more scientific guidance. Finally, they argued that face-to-face counselling can help people learn to cope with stress better. It is worth noting that some teachers think that their workload is already too heavy and intensive training will consume more of their time and energy, thus making them even busier. Therefore, when training teachers in occupational health care, attention should be paid not to increase the pressure on teachers thereby adding to the burden.

\section{CONCLUSION}

The aim of this study was to investigate the knowledge of Chinese primary school teachers on occupational health problems. This study adopted a mixed methodology and designed a questionnaire containing quantitative and qualitative questions to achieve the research aims. The study fills a gap in the literature on teacher occupational health. Understanding the current situation of teachers' knowledge to deal with occupational health problems, combined with the conclusions of other studies, can enable people to play a better role in helping teachers' occupational health.

Here are some of the findings. First of all, most Chinese primary school teachers have a good knowledge of dealing with occupational health problems, and only a minority of them have very good or poor knowledge. Their knowledge is not affected by age and working years, and the knowledge level of male and female teachers is similar, but there are still great differences in some items. Secondly, Chinese primary teachers have a poor grasp of the following points: the dangers of frequent clearing throat with a small cough, treatments for voice disorders, behaviours before going to bed, the relationship between depression and insomnia, the influence of alcohol on sleep, getting up regularly, the relationship between stress and insomnia, and the effects of exercises and massage for patients with musculoskeletal disorders. However, some actions are not misjudged, but rather teachers simply do not always know the right thing to do in certain situations. Finally, most primary school teachers in China suffer from occupational health problems, many of them from two or more. They think that the training of teachers' occupational health would be helpful to them and they express their desire to participate in such training. Additionally, they put forward some training topics and training methods that they are interested in. It is worth noting that when training teachers in occupational health care, attention should be paid not to increase the pressure of teachers and make it a burden.

\section{REFERENCES}

[1] D. Bicout, D. Rieutort, L. Faisandier, V. Bonneterre, and R. Gaudemaris, S15-4 spectrosome of occupational health problems, in: Occupational and Environmental Medicine, 2016, 73.

[2] P.N. Erick, D.R. Smith, A systematic review of musculoskeletal disorders among schoolteachers, in: BMC Musculoskeletal Disorders, 2011, 12(1), 260. doi:10.1186/1471-2474-12-260.

[3] S. Gardner, Stress among prospective teachers: A review of the literature, in: Australian Journal of Teacher Education, 2010, 35(8), 17-28.

[4] C. Gadepalli, C.Fullwood, F. Ascott and J. J. Homer, Voice burden in teachers and non-teachers in a UK population: A questionnaire-based survey, in: 
Clinical Otolaryngology, 2019, 44(6), 1045-1058. doi:10.1111/coa.13437.

[5] K. Scheuch, E. Haufe and R. Seibt, Teachers' health in: Dtsch. Ärztebl. Int. 2015, 112 347-356. 10.3238/arztebl.2015.0347.

[6] M. Kunter, U. Klusmann, J. Baumert, D. Richter, T. Voss, and A. Hachfeld, Professional competence of teachers: Effects on instructional quality and student development, in: Journal of Educational Psychology, 2013, 105(3), 805-820. https://doi.org/10.1037/a0032583

[7] A. Hinz, M. Zenger, E. Brähler, S. Spitzer, K. Scheuch and R. Seibt, Effort-Reward imbalance and mental health problems in 1074 german teachers, compared with those in the general population, in: Stress and Health, 2016, 32(3), 224230. doi:10.1002/smi.2596

[8] L. Allsop, T. Ackland, The prevalence of playingrelated musculoskeletal disorders in relation to piano players' playing techniques and practising strategies, in: Music Performance Research 2010, 3(1):61-78.

[9] N. I. A. Samad, H. Abdullah, S. Moin, S. B. M. Tamrin and Z. Hashim, Prevalence of low back pain and its risk factors among schoolteachers, in: American Journal of Applied Sciences, 2010, 7(5):634-639.

[10] J. P. Cardoso, I. De Queiroz Batista Ribeiro, T. Maria de Araújo, F. M. Carvalho, E. José Farias Borges dos Reis, Prevalence of musculoskeletal pain among teachers, in: Revista Brasileira de Epidemiologia, 2009, 12(4):1-10.

[11] T. W. Chiu, K. T. Lau, C. W. Ho, M. C. Ma, T. F. Yeung and P. M. Cheung, A study on the prevalence of and risk factors for neck pain in secondary school teachers, in: Public Health,2006, 120(6):563-565.

[12] I. Arvidsson, J. Gremark Simonsen, C. Dahlqvist, A. Axmon, B. Karlson, J. Björk and C. Nordander, Cross-sectional associations between occupational factors and musculoskeletal pain in women teachers, nurses and sonographers, in: BMC musculoskeletal disorders, 2016, 17, 35. https://doi.org/10.1186/s12891-016-0883-4

[13] J. Shuai, P. Yue, L. Li, F. Liu and S. Wang, Assessing the effects of an educational program for the prevention of work-related musculoskeletal disorders among schoolteachers, in: BMC Public Health, 2014, 14(1211):1-9.

[14] P. Yue, F. Liu, and L. Li, Neck/shoulder pain and low back pain among schoolteachers in China, prevalence and risk factors, in: BMC Public Health, 2012, 12:789.

[15] S. Chaiklieng, P. Suggaravetsiri, Risk factors for repetitive strain injuries among schoolteachers in Thailand, in: Work: A J Prev, Assess Rehabil 2012, 41:2510-2515.

[16] J. I. Halonen, R. Shiri, M. Mänty, H. Sumanen, S. Solovieva, E. Viikari-Juntura, M. Kähönen, T. Lehtimäki, O. T. Raitakari and T. Lallukka, Exposure to heavy physical work from early to later adulthood and primary healthcare visits due to musculoskeletal diseases in midlife: a register linked study, in: BMJ open, 2019, 9(8), e031564. https://doi.org/10.1136/bmjopen-2019-031564.

[17] I. Bogaert, K. De Martelaer, B. Deforche, P. Clarys and E. Zinzen, Associations between different types of physical activity and teachers' perceived mental, physical, and work-related health, in: BMC public health, 2014, 14, 534. https://doi.org/10.1186/1471-2458-14-534.

[18] M. Ohta, T. Mizoue, N. Mishima and M. Ikeda, Effect of the physical activities in leisure time and commuting to work on mental health, in: J Occup Health, 2007, 49(1):46.-52.

[19] American Psychiatric Association, DSM-IV-TR: manual de diagnóstico e estatística das perturbações mentais. 4.a ed. Lisboa: Climepsi, 2002.

[20] M. M. Ohayon, Epidemiology of insomnia: what we know and what we still need to learn, in: Sleep Med Rev. 2002, 6:97-111.

[21] C. L. Drake, R. Timothy and R. Thomas, Insomnia causes, consequences, and therapeutics: An overview. Depression and Anxiety, 12/2003, Volume 18, Issue 4.

[22] J. Walsh, Clinical and socioeconomic correlates of insomnia. J Clin Psychiatry, 2004, 64:13-9.

[23] L. C. Johnson, M. W. Church, D. M. Seales and V. S. Rossiter, Auditory arousal thresholds of good sleepers and poor sleepers with and without flurazepam. Sleep, 1979, 1:259-270.

[24] A. Bannai, S. Ukawa and A. Tamakoshi, Hokkaido University Graduate School of Medicine, \& Department of Public Health. Long working hours and sleep problems among public junior high school teachers in japan. Journal of Occupational Health, 2015, 57(5), 457-464. doi:10.1539/joh.150053-OA.

[25] J. Cheng, T. Wang, F. Li, Y. Xiao, J. Bi, J. Chen and $X$. Zhao, Self-rated health status and subjective 
health complaints associated with health-promoting lifestyles among urban chinese women: A crosssectional study. PloS One, 2015, 10(2), e0117940. doi: 10.1371/journal.pone.0117940.

[26] C. Pereira, C. Almeida, N. Veiga and O. Amaral, Prevalence and determinants of insomnia symptoms among schoolteachers. Atención Primaria, 2014, Volume 46.

[27] M. T. Smith, M. L. Perlis, A. Park, M. S. Smith, J. Pennington, D. E. Giles and D. J. Buysse, Comparative meta-analysis of pharmacotherapy and behavior therapy for persistent insomnia. The American journal of psychiatry, 2002, 159(1), 511. https://doi.org/10.1176/appi.ajp.159.1.5.

[28] M. L. Perlis, M.T. Smith, D. O. Cacialli, S. Nowakowski and H. Orff, On the comparability of pharmacotherapy and behavior therapy for chronic insomnia. Commentary and implications. J Psychosom Res 2003 54:51-59.

[29] N. S. Delcor, T. M. Araújo, E. J. F. B. Reis, L. A. Porto, F. M. Carvalho, M. O. Silva, L. Barbalho and M. A. Andrade, Condições de trabalho e saúde dos professores da rede particular de ensino de Vitória da Conquista, Bahia, Brasil. Cad Saúde Pública; 2004, 20(1):187-96.

[30] M. Angelillo, G. Di Maio, G. Costa, N. Angelillo and U. Barillari, Prevalence of occupational voice disorders in teachers. Journal of preventive medicine and hygiene, 2009, 50(1), 26-32.
[31] N. Roy, R. M. Merrill, S. Thibeault, R. A. Parsa, S. D. Gray, and E. M. Smith, Prevalence of voice disorders in teachers and the general population, in: Journal of speech, language, and hearing research: JSLHR,2004, 47(2), 281-293. https://doi.org/10.1044/1092-4388(2004/023).

[32] C. Kovacic, Voice education in teacher training: an investigation into the knowledge about the voice and voice care in teacher-training students, in: Journal of Education for Teaching, 2005, vol. 31, No. 2, pp. 87-97.

[33] O. M. Duffy, D. E. Hazlett, The impact of preventive voice care programs for training teachers: A longitudinal study, in: Journal of Voice, 2004, 18(1), 63-70. doi:10.1016/S08921997(03)00088-2.

[34] N. Roy, D. M. Bless, Personality traits and psychological factors in voice pathology: a foundation for future research, in: Journal of Speech, Language, and Hearing Research, 2000, 43(3): 737-748.

[35] K. Scheuch, T. Pardula, G. C. Winkler and R. Seibt, Betriebsärztliche Betreuung von Lehrkräften, in: Präv Gesundheitsf 2016 11, 147153.

[36] G. Kovacic, Subjective voice complaints among schoolteachers in: F. De Jong (Ed.) De stem in het onderwijs-Multidimensionaal-multidisciplinair UMC St Radboud Nijmegen 200399110. 